\title{
EFFECT OF A DIELECTRIC BARRIER ON THE ELECTRIC FIELD DISTRIBUTION IN HIGH-VOLTAGE COMPOSITE INSULATION OF ELECTRIC MACHINES
}

\begin{abstract}
Introduction. Modern high-voltage systems for composite insulation of electrical machines consist of tape glass mica paper materials (dry or pre-impregnated). The electrical characteristics of a multilayer composite insulation system are determined by both the fractional content of the individual components and their electrophysical properties. Purpose. The analysis of the influence of electrophysical characteristics and thickness (fraction) of the dielectric barrier on the distribution of the electric field in the composite high-voltage insulation of electrical machines. Methodology. Simulation of surface charge accumulation at the interface between the substrate and the dielectric barrier is based on the Maxwell-Wagner theory for interfacial polarization. Practical value. The influence of the electrophysical characteristics and thickness of the dielectric barrier on the distribution of the electric field has been established. In the steady state, the electric field strength in the dielectric barrier exceeds the average value by $50 \%$. In the region of small transition times (up to $1 \mathrm{~s}$ ), the relative dielectric constant of the barrier has a significant effect on the distribution of the electric field. The use of a dielectric barrier with a higher dielectric constant and fractional content in comparison with the substrate leads to an increase in electric field strength by $5 \%$ relative to the average value in composite insulation. Experimental studies of the long-term electrical strength of glass mica-belt ribbons in the cured (thermosetting) state are consistent with the simulation results. Composite insulation based on glass fiber mica tape with a high content of the mica barrier and fiberglass of smaller thickness has (8-16) \% higher values of long-term electric strength. References 9, figures 5.
\end{abstract}

Key words: high-voltage composite insulation, dielectric barrier, fiberglass substrate, interfacial polarization, electric field distribution, long-term electrical strength.

Представлены результаты распределения электрического поля в высоковольтной композитной изоляции на основе предложенной математической модели накопления поверхностного заряда на границе раздела подложка - барьер. В установившемся режиме напряженность электрического поля в диэлектрическом барьере может превышать среднее значение на 50 \% в зависимости от электрофизических характеристик и толцины компонентов. Показано, что в области малых времен переходного процесса на характер распределения электрического поля влияют как относительная диэлектрическая проницаемость, так и толщина диэлектрического барьера. Экспериментальная проверка выполнена для пяти типоразмеров стеклослюдобумажной ленты по 5-ть макетов в каждой. Установлено, что композитная изоляция с повышенным содержанием слюдинитового барьера и стеклотканью меньщей толщины имеет на (8-16) \% более высокие значения длительной электрической прочности. Библ. 9, рис. 5.

Ключевые слова: высоковольтная композитная изоляция, диэлектрический барьер, стекловолокнистая подложка, межфазная поляризация, распределение электрического поля, длительная электрическая прочность.

Introduction. Modern high-voltage systems for composite insulation of electrical machines consist of ribbon glass mica paper materials (dry or preimpregnated) $[1,2]$. The main function of such insulation is the preservation of long-term electrical strength under the conditions of long-lasting thermal, mechanical and thermomechanical effects. High-voltage insulation should also have the necessary level of manufacturability and relatively low cost while maintaining high technical and operational characteristics.

Use as a dielectric barrier of mica paper is costeffective, as it is made from waste of scarce and fairly expensive splinter mica [1]. Compared with materials based on splinter mica, micaceous and mica plastics papers have a greater thickness uniformity, increased and more uniform electrical strength. The combination of good elasticity and mechanical strength allows to obtain a dense, monolithic thermosetting insulation [2]. Flat mica particles form a dielectric barrier and, depending on the conditions, are bound by various impregnating compositions and substrates. The binder can be introduced into the composition of the tape either in advance, then the tape is called pre-impregnated (Resin Rich), or introduced into the dry tapes after they have been processed in the process of vacuum-pressure impregnation [1].
Epoxy resins (diano, cycloaliphatic and epoxy drawing) are used as a binder, which have high mechanical properties, good adhesion to various materials, sufficient heat resistance (class $\mathrm{B}$ and $\mathrm{F}$ ) and corona resistance, have a slight shrinkage ratio (3-5) \% [2].

The mechanical strength is provided by the glass fabric substrate, which is a reinforcing material in such a system. It also contains most of the binder in the case of impregnated tape. Composite insulation, made with the use of glass fiber materials, has an increased tensile strength and flexural strength. Glass fiber materials are highly thermally resistant $[1,2]$.

The electrical characteristics of a multilayer composite insulation system are determined by both the fractional content of the individual components and their electrophysical properties.

Problem definition. The real interface between the substrate and the dielectric barrier has a surface layer of finite thickness, within which the thermodynamic parameters (concentration of components, pressure and temperature) undergo drastic changes. The surface layers of each phase with a thickness of about $0.5 \mathrm{~nm}$ have special properties, since they are in the field of action of the molecular forces of the neighboring phase (the socalled Rebinder effect) [3].

(C) G.V. Bezprozvannych, A.N. Boyko, A.V. Roginskiy 
The desire of a heterogeneous system to reduce the surface energy causes an appropriate orientation of polar molecules, ions and electrons in the boundary layer, as a result of which the contacting phases acquire charges of opposite sign, but of equal value. At the interface between the substrate and the dielectric barrier, as on the interfacial surfaces, a double electric layer arises as a result of the interaction of the contacting phases due to excess surface energy [4] with the corresponding electric potential, surface charge density, capacity [5-7].

The goal of the paper is analysis of the influence of electrophysical characteristics and thickness (fraction) of the dielectric barrier on the distribution of the electric field in the composite high-voltage insulation of electrical machines.

Mathematical model of surface charge accumulation at the flat interface between two dielectrics. A high-voltage thermosetting composite insulation of electrical machine can be represented in the form of two layers of dielectric: a glass fiber substrate (1) with an impregnating compound (3) and a mica paper tape (2) as a dielectric barrier (Fig. 1). The anisotropy of the properties of mica in this case is weakly expressed.

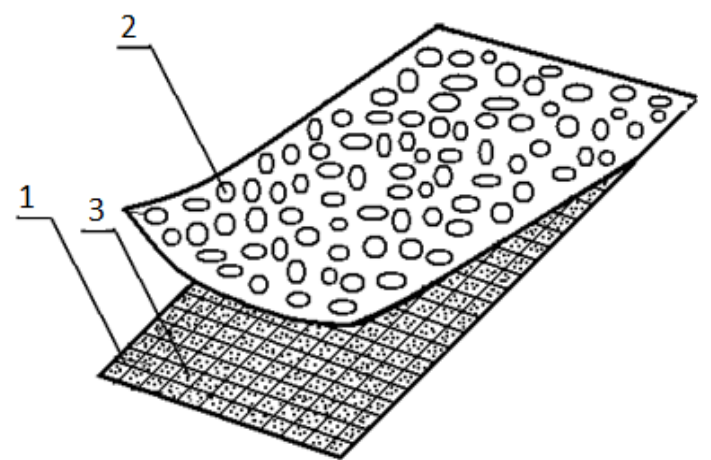

Fig. 1. Schematic representation of the three-component insulation by a double layer tape

The most common approach in simulating the accumulation of surface charge at the interface of two dielectric media is based on the Maxwell-Wagner theory for interfacial polarization [8].

The hypothetical configuration of the interface between two flat isotropic dielectrics with electrodes is represented by a Maxwell capacitor (Fig. 2). In such a system, the insulation properties change depending on the step function at the interface of the media [8].

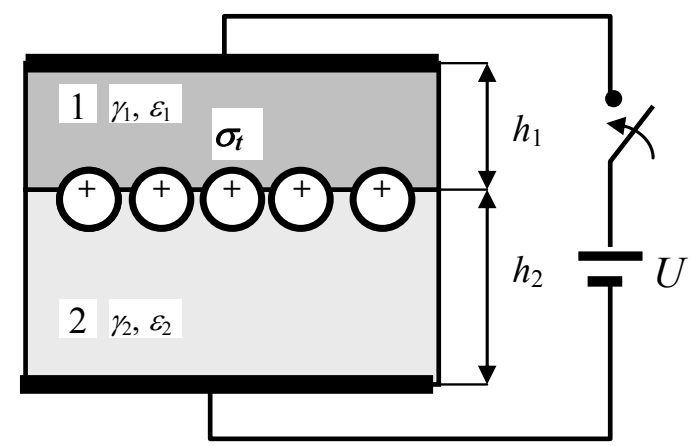

Fig. 2. Representation of the accumulation of surface charges at the interface of two isotropic dielectrics when switched on under constant voltage $U$
At the dielectric interface, the dielectric permeability $\varepsilon$ (or the polarization vector) varies in steps $[8,9]$. The jump of the normal component of the electric displacement vector $\boldsymbol{D}$ is equal to the surface density $\sigma$ of electric charges. The tangential component of the electric field strength vector is continuous at any interface

$$
D_{2 n}-D_{1 n}=\sigma, E_{1 t}=E_{2 t},
$$

where $D_{2 n}, D_{1 n}$ are the normal components of the electric displacement vector: $D_{2 n}=\varepsilon_{0} \varepsilon_{2} E_{2 n}, \quad D_{1 n}=\varepsilon_{0} \varepsilon_{1} E_{1 n}$, $\varepsilon_{0}=8.85 \cdot 10^{-12} \mathrm{~F} / \mathrm{m}$ is the electric constant; $\varepsilon_{1}, \varepsilon_{2}$ are the dielectric permeabilities of dielectrics, $\sigma$ is the surface density of electric charges; $E_{1 n}, E_{2 n}$ are the normal, $E_{1 t}, E_{2 t}$ are the tangential components of the electric field strength vector of the first and the second dielectrics, respectively.

At the moment of switching on the capacitor to the voltage source $U$, the surface density $\sigma$ of electric charges is zero, as a result, in accordance with (1), the electric field strength in the layers is proportional to the dielectric permeability [8]

$$
E_{1 n} \varepsilon_{1}=E_{2 n} \varepsilon_{2} \text {. }
$$

At the next instant, the conduction current with the corresponding density $J$ begins to influence the distribution of the electric field in the layers

$$
J_{1}=\gamma_{1} E_{1}, \quad J_{2}=\gamma_{2} E_{2},
$$

where $\gamma_{1}$ and $\gamma_{2}$ are the conductivities of each dielectric, $\mathrm{S} / \mathrm{m}$.

Since the current densities are not equal (the electrophysical properties of dielectrics are different), a space charge accumulates at the interface between the dielectrics. The transient ends with the balancing of the currents $J_{1}$ and $J_{2}$, as well as the stabilization of the surface charge at the interface of the dielectrics. For the steady state, the electric field strength in the layers is proportional to the conductivity

$$
\gamma_{1} E_{1}=\gamma_{2} E_{2} \text {. }
$$

From the initial moment and steady state, the total current in the first and second dielectrics is the same and has two components: active, which is caused by conduction current (leakage current), and reactive, due to displacement current (absorption current). Thus, the total current density will be determined as

$$
J=\gamma_{1} E_{1}+\varepsilon_{0} \varepsilon_{1} \frac{d E_{1}}{d t}=\gamma_{2} E_{2}+\varepsilon_{0} \varepsilon_{2} \frac{d E_{2}}{d t} .
$$

The sum of the voltage drop across each layer is equal to the applied DC voltage

$$
E_{1} h_{1}+E_{2} h_{2}=U
$$

where $h_{1}, h_{2}$ are the dielectric thickness.

When combining (5) and (6), the differential equation for $E_{1}$ is

$$
\frac{d E_{1}}{d t} \varepsilon_{0}\left(\varepsilon_{1} h_{2}+\varepsilon_{2} h_{1}\right)+E_{1}\left(\gamma_{1} h_{2}+\gamma_{2} h_{1}\right)=\gamma_{2} U,
$$

whose solution is searched in the form

$$
E_{1}(t)=A e^{-\left(\frac{\gamma_{1} h_{2}+\gamma_{2} h_{1}}{\varepsilon_{0}\left(\varepsilon_{1} h_{2}+\varepsilon_{2} h_{1}\right)} t\right)}+U \frac{\gamma_{2}}{\left(\gamma_{1} h_{2}+\gamma_{2} h_{1}\right)},
$$

where $A$ is the integration constant, which, taking into account the initial conditions at time $t=0$ and (2), (6) is defined as 


$$
A=U\left(\frac{\varepsilon_{2}}{\varepsilon_{1} h_{2}-\varepsilon_{2} h_{1}}-\frac{\gamma_{2}}{\gamma_{1} h_{2}+\gamma_{2} h_{1}}\right) .
$$

After substituting (9) into (8), the electric field strength in the first layer of a two-layer dielectric varies with time in accordance with (10)

$$
E_{1 t}=U \frac{\gamma_{2}}{\gamma_{1} h_{2}+\gamma_{2} h_{1}}+U \frac{h_{1} \cdot\left(\varepsilon_{2} \gamma_{1}-\varepsilon_{1} \gamma_{2}\right)}{\left(\varepsilon_{1} h_{2}+\varepsilon_{2} h_{1}\right) \cdot\left(\gamma_{1} h_{2}+\gamma_{2} h_{1}\right)} e^{-t / \tau}
$$

and in the second one in accordance with (11)

$$
E_{2 t}=U \frac{\gamma_{1}}{\gamma_{1} d_{2}+\gamma_{2} d_{1}}+U \frac{d_{2} \cdot\left(\varepsilon_{1} \gamma_{2}-\varepsilon_{2} \gamma_{1}\right)}{\left(\varepsilon_{1} d_{2}+\varepsilon_{2} d_{1}\right) \cdot\left(\gamma_{1} d_{2}+\gamma_{2} d_{1}\right)} e^{-t / \tau}
$$

where $\tau$ is the time constant, $\mathbf{s}$

$$
\tau=\varepsilon_{0} \frac{\varepsilon_{1} h_{2}+\varepsilon_{2} h_{1}}{\gamma_{1} h_{2}+\gamma_{2} h_{1}} .
$$

The density of the total current, which consists of the current of absorption and leakage due to the presence of free charges, is determined by the formula (13)

$$
\begin{aligned}
& J(t)=U \frac{h_{1} h_{2}\left(\varepsilon_{1} \gamma_{2}-\varepsilon_{2} \gamma_{1}\right)}{\left(\varepsilon_{1} h_{2}+\varepsilon_{2} h_{1}\right)^{2}\left(\gamma_{1} h_{2}+\gamma_{2} h_{1}\right)} \times \\
& \times \exp (-t / \tau)+U \frac{\gamma_{1} \gamma_{2}}{\gamma_{1} h_{2}+\gamma_{2} h_{1}}=J_{a b s}+J_{\text {cond }} .
\end{aligned}
$$

The time variation of the surface charge density $\sigma(t)$ at the interface between two dielectrics can be written as

$$
\sigma(t)=\varepsilon_{o} \frac{\varepsilon_{1} \gamma_{2}-\varepsilon_{2} \gamma_{1}}{\gamma_{1} h_{2}+\gamma_{2} h_{1}} \cdot U\left(1-e^{-t / \tau}\right) .
$$

The effect of electrophysical characteristics and thickness of the dielectric barrier on the distribution of the electric field in high-voltage composite insulation. Fig. 3 shows the simulation results for two cases: curves 1 - the identity of the electrical characteristics of the barrier and the substrate: $\varepsilon_{1}=\varepsilon_{2}=$ $=4.5 ; \quad \gamma_{1}=\gamma_{2}=2 \cdot 10^{-13} \mathrm{~S} / \mathrm{m} ;$ curves 2,2 '- different: $\varepsilon_{1}=4.5 ; \varepsilon_{2}=3.8 ; \gamma_{1}=2 \cdot 10^{-13} \mathrm{~S} / \mathrm{m}, \gamma_{2}=2 \cdot 10^{-12} \mathrm{~S} / \mathrm{m}$. Indexes 1 relate to the barrier, 2 - to the substrate. The thickness of the dielectric barrier is $h_{1}=0.1 \mathrm{~mm}$, of the glass fiber substrate is $h_{2}=0.05 \mathrm{~mm}$. Curve 2 corresponds to the distribution of the electric field in the barrier, curve 2' in the substrate (Fig. 3,b). The calculations were performed for the average electric field strength $E_{\text {mid }}=15 \mathrm{kV} / \mathrm{mm}$ in composite insulation.

If the electrical characteristics are identical, surface charges do not accumulate at the interface between dielectric media (curve 1, Fig. 3,a) and the electric field is equal to the average value: $E=E_{\text {mid }}=15 \mathrm{kV} / \mathrm{mm}$ (curve 1, Fig. 3,b). The transient is absent.

In the case of different characteristics, a transient of a duration of about $10 \mathrm{~s}$ is observed. In the steady state, the surface charge density is $0.85 \mathrm{mC} / \mathrm{m}^{2}$ (curve 2, Fig. 3,a), the electric field strength in the dielectric barrier exceeds the average value by $50 \%$ (curve 2 , Fig. $3, b$ ), in the substrate it is insignificantly small (curve 2', Fig. 3,b).

Fig. 4 shows the dynamics of the time variation of the electric field distribution with varying conductivity, relative dielectric permeability and thickness of the dielectric barrier.
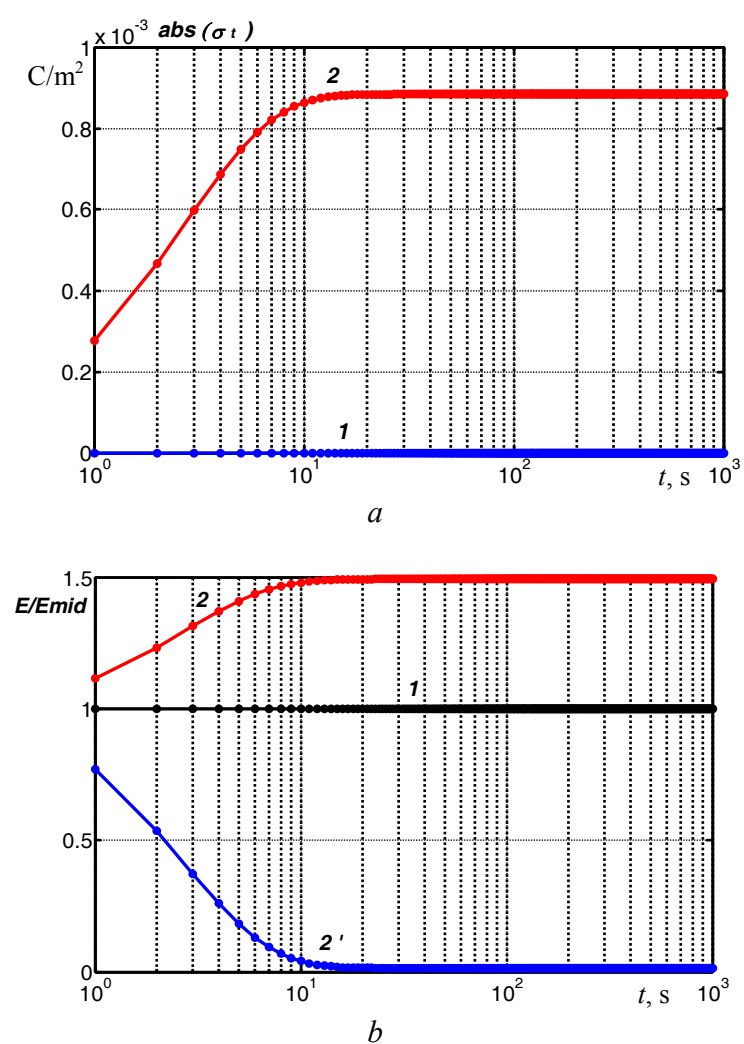

Fig. 3. The distribution of surface charge density $(a)$ and the electric field strength $(b)$ at the interface between the substrate and the dielectric barrier

In Fig. 4, $a, b$ curves 1 and 2 correspond: $\varepsilon_{1}=4.5$, $\varepsilon_{2}=3.8, \gamma_{1}=2 \cdot 10^{-13} \mathrm{~S} / \mathrm{m}, \gamma_{2}=2 \cdot 10^{-12} \mathrm{~S} / \mathrm{m}$; curves 1 ' and 2 ' $-\varepsilon_{1}=4.5, \varepsilon_{2}=3.8, \gamma_{1}=2 \cdot 10^{-13} \mathrm{~S} / \mathrm{m}, \gamma_{2}=2 \cdot 10^{-11} \mathrm{~S} / \mathrm{m}$, respectively. The thickness of the dielectric barrier is assumed to be $h_{1}=0.1 \mathrm{~mm}$, of the substrate is $h_{2}=0.05 \mathrm{~mm}$. The share content of mica in this case is $67 \%$ of the total volume of composite insulation.

The effect of relative dielectric permeability and barrier thickness on the distribution of the electric field is shown in Fig. 4,c. Curves 1 and 2 correspond to the characteristics: $\varepsilon_{1}=4.5, \varepsilon_{2}=3.8, \gamma_{1}=2 \cdot 10^{-13} \mathrm{~S} / \mathrm{m}$, $\gamma_{2}=2 \cdot 10^{-12} \mathrm{~S} / \mathrm{m}, h_{1}=0.1 \mathrm{~mm}, h_{2}=0.05 \mathrm{~mm}$. Curves 1 , and 2': $\varepsilon_{1}=3.8, \quad \varepsilon_{2}=4.5, \gamma_{1}=2 \cdot 10^{-13} \mathrm{~S} / \mathrm{m}$, $\gamma_{2}=2 \cdot 10^{-12} \mathrm{~S} / \mathrm{m} ; h_{1}=0.1 \mathrm{~mm}, h_{2}=0.05 \mathrm{~mm}$. Curves 1 "' and 2', $\varepsilon_{1}=4.5, \varepsilon_{2}=3.8, \gamma_{1}=2 \cdot 10^{-13} \mathrm{~S} / \mathrm{m}, \gamma_{2}=2 \cdot 10^{-12} \mathrm{~S} / \mathrm{m}$, $h_{1}=0.05 \mathrm{~mm}, h_{2}=0.1 \mathrm{~mm}$.

In the region of short transient times $(10 \mathrm{~ms}-1 \mathrm{~s})$, the nature of the distribution of the electric field is significantly affected by the ratio between the dielectric permeabilities of the barrier and the substrate, with their constant thickness. In the case when $\varepsilon_{1}<\varepsilon_{2}$, the electric field strength in the barrier exceeds the average value of 1.05 , while in the substrate it is 1.1 times, respectively (compare curves 1' and 2, Fig. 4,c). This fact is especially important when working under alternating voltage: a dielectric barrier provides long-term dielectric strength of composite insulation.

A decrease in the thickness of the dielectric barrier (fractional content), provided that $\varepsilon_{1}>\varepsilon_{2}$, leads to an increase in the electric field, although it «unloads» the substrate electrically (compare curves 1', and 1' in Fig. 4,c). 

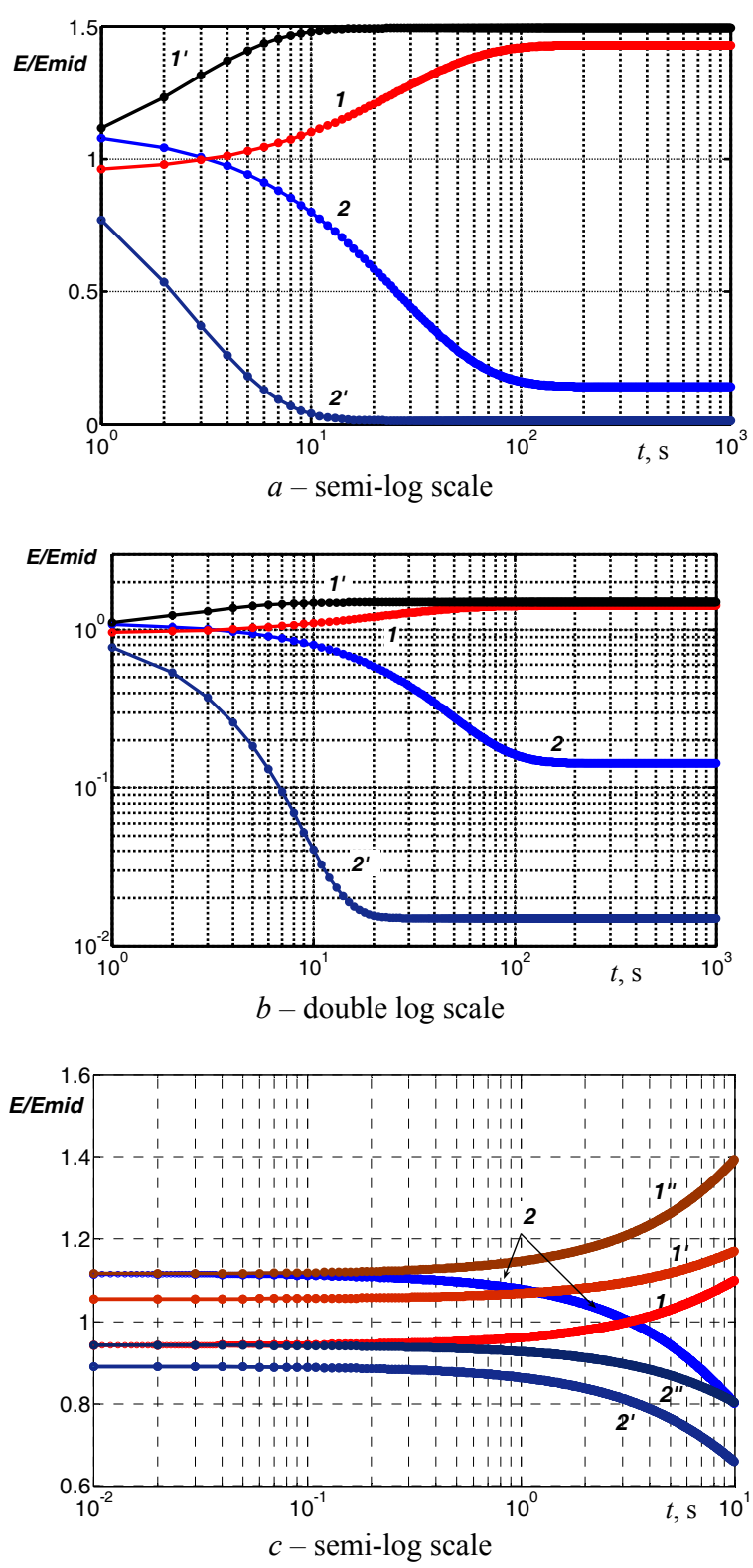

Fig. 4. The effect on the distribution of the electric field of the electrophysical characteristics and thickness of the components at the interface between the substrate and the dielectric barrier

Experimental verification of the effect of the fractional content of mica paper tape on the long-term electrical strength of composite high-voltage insulation samples. For testing tapes in the cured state, 5 layouts were made with each glass-mica paper tape of different thickness from different manufacturers: $1-h=0.15 \mathrm{~mm}$, $2-h=0.14 \mathrm{~mm}, 3-h=0.14 \mathrm{~mm}, 4-h=0.18 \mathrm{~mm}$, $5-h=0.18 \mathrm{~mm}$.

The layouts are copper busbars of $6 \times 30 \times 800 \mathrm{~mm}$ size, which are isolated on the ЛИСП-4 tape insulation machine with a tape heated to temperature of $50-60{ }^{\circ} \mathrm{C}$ and tension of 40-60 N. Layouts, covered with slats on wide faces, are pressured by hydrostatic method. Longterm electrical strength of the finished layouts is determined with continuous exposure under voltage from the calculation $15 \mathrm{kV} / \mathrm{mm}$ at industrial frequency.

The correctness of the adequacy of the results of modeling on direct current by experimental research on alternating current is permissible, since in the region of short transient times, the influence of both the electrophysical characteristics and the fraction of the dielectric barrier on the distribution of the electric field in the composite insulation is manifested (see Fig. 4,a-c) [long-term electrical strength at $50 \mathrm{~Hz}$ alternating current is lower in comparison with constant current due to large losses due to the polarization process].

Fig. 5 shows the results of tests of long-term electrical strength of the layouts, depending on the thickness of the composite insulation. The integral distribution functions of long-term electric strength are shown in Fig. 5, $a$, average values in Fig. 5, $b$.
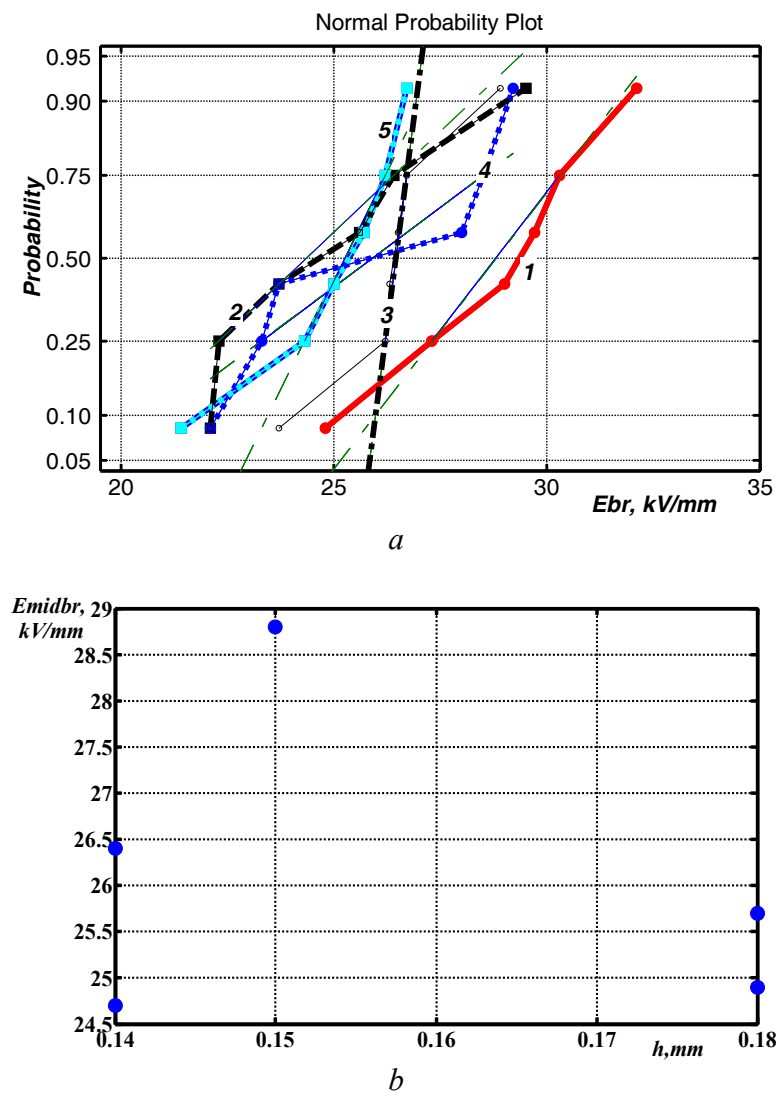

Fig. 5. The effect of the micaceous barrier on the long-term electrical strength of the composite high-voltage insulation of electrical machines

The smallest scatter of the values of the breakdown electric strength is for insulation systems with thickness $h=0.14 \mathrm{~mm}$ (curve 3, Fig. 5,a), which may be due to a more uniform thickness of glass-mica paper tape due to the use of a different type of binder. The slope of the integral distribution function of the electrical strength of the layouts with this insulation system differs significantly from the rest (compare curve 3 with curves 1, 2, 4, 5 in Fig. 5,a).

For sample thickness of composite insulation $h=0.15 \mathrm{~mm}$ (curve 1, Fig. 5,a) the greatest value of longterm electric strength is observed: at the level of $50 \%$ probability, the average value is $28.75 \mathrm{kV} / \mathrm{mm}$ (Fig. 5,b). In this layout, a tape with a high content of the micaceous barrier and a less thick fiberglass (in accordance with the technical description on the tape) are used.

Conclusions. For the first time, the distribution of the electric field in high-voltage composite insulation of 
electrical machines is obtained on the basis of the proposed mathematical model of surface charge accumulation at a flat interface between the substrate and the dielectric barrier.

It is established that in the steady state the electric field strength in the barrier exceeds the average value by $50 \%$ depending on the electrophysical characteristics and thickness of the components.

In the region of short transient times (up to $1 \mathrm{~s}$ ), the relative dielectric permeability of the barrier has a significant effect on the distribution of the electric field in composite insulation. The use of a dielectric barrier with higher dielectric permeability and fractional content in comparison with the substrate leads to an increase of $5 \%$ of the electric field relative to the average value.

Experimental studies of the long-term electrical strength of layouts of glass mica tapes in the cured (thermosetting) state are consistent with the simulation results.

Composite insulation based on glass fiber mica tape with a high content of the mica barrier and fiberglass of smaller thickness has $(8-16) \%$ higher values of longterm electrical strength.

\section{REFERENCES}

1. Ogonkov V.G., Serebryannikov S.V. Elektroizoliatsionnye materialy $i$ sistemy izoliatsii dlia elektricheskikh mashin. $V$ dvukh knigakh. Kn. 2 [Electrical insulation materials and insulation systems for electrical machines. In 2 books. Book 2]. Moscow, Publishing house MEI, 2012. 304 p. (Rus).

2. Pak V.M., Trubachev S.G. Novye materialy $i$ sistemy izoliatsii vysokovol'tnykh elektricheskikh mashin [New materials and systems for isolation of high-voltage electrical machines]. Moscow, Energoatomizdat Publ., 2007. 416 p. (Rus).

3. Rebinder P.A. O vliianii izmenenii poverkhnostnoi energii na spainost', tverdost' $i$ drugie svoistva kristallov [On the effect of changes in surface energy on the cleavage, hardness and other properties of crystals]. Congress of Russian physicists. The list of reports submitted to the congress, with a brief summary. Moscow - Leningrad, 1928. 29p. (Rus).

4. Gibbs J.V. Termodinamika. Statisticheskaia mekhanika [Thermodynamics. Statistical mechanics]. Moscow, Nauka Publ., 1982. 584 p. (Rus).

5. Mikhailov V.M. Initial relations and approximate boundary conditions for calculating the field in systems with thin layers. Electricity, 2007, no.3, pp. 49-55. (Rus).

6. Kim Yong Dar, Kalmykov V.L. Study of the electric field of an insulating structure with thin extended areas. Bulletin of NTU «KhPI», 2005, no.42, pp. 65-70. (Rus).

7. Bezprozvannych G.V., Boyko A.N. Distribution of surface density of charges on the interface between contacting isolated conductors of the cables. Technical Electrodynamics, 2014, no.6. pp. 18-23. (Rus).

8. Hippel A.R. Dielektriki $i$ volny [Dielectrics and waves]. Moscow, Publ. House of Foreign Literature, 1960. 439 p. (Rus).

9. Demirchian K.S., Neiman L.R., Korovkin N.V., Chechurin V.L. Teoreticheskie osnovy elektrotekhniki: V 3-kh t. Uchebnik dlia vuzov [Theoretical bases of electrical engineering. In 3 vols.]. St. Petersburg, Piter Publ, 2003. 463 p. (Rus).

Received 14.07.2018

G.V. Bezprozvannych ${ }^{1}$, Doctor of Technical Science, Professor, A.N. Boyko ${ }^{2}$, Candidate of Technical Science,

A.V. Roginskiy ${ }^{3}$, Postgraduate Student,

${ }^{1}$ National Technical University «Kharkiv Polytechnic Institute», 2, Kyrpychova Str., Kharkiv, 61002, Ukraine,

e-mail: bezprozvannych@kpi.kharkov.ua

${ }^{2}$ Company «WebMeridian in Ukraine»,

13, Chernyshevskogo Str., Kharkiv, 61002, Ukraine,

${ }^{3}$ SE Plant Electrotyazhmash,

299, Moskovsky Ave., Kharkiv, 61089, Ukraine,

e-mail: roginskiy.av@gmail.com

How to cite this article:

Bezprozvannych G.V., Boyko A.N., Roginskiy A.V. Effect of a dielectric barrier on the electric field distribution in high-voltage composite insulation of electric machines. Electrical engineering \& electromechanics, 2018, no.6, pp. 63-67. doi: 10.20998/2074-272X.2018.6.09. 